\title{
Grupos terapêuticos na abordagem gestáltica: uma proposta de atuação clínica em comunidades
}

\section{Therapeutical groups in gestaltic approach: a proposal of clinical interaction in communities}

\section{Claudia Lins Cardoso*}

Professora Adjunta do Departamento de Psicologia da Faculdade de Filosofia e Ciências Humanas da Universidade Federal de Minas Gerais/UFMG - Belo Horizonte, MG, Brasil

\begin{abstract}
Resumo
Este artigo origina-se no projeto de extensão Inserção do Psicólogo no Programa de Saúde da Família, desenvolvido de 1998 a 2004, com pacientes diabéticos e hipertensos, numa parceria entre o Departamento de Psicologia da Universidade Federal de Minas Gerais e a Secretaria Municipal de Saúde de Vespasiano (MG). Tem por objetivo apresentar a proposta de grupos terapêuticos no trabalho clínico com pessoas pertencentes a comunidades carentes, a partir dos pressupostos da Gestalt-terapia. Para isso, buscou explicitar como a fundamentação filosófica da Gestalt-terapia e os pressupostos teóricos sustentaram a metodologia e a atuação do psicólogo clínico, no sentido de ampliar a consciência dos membros do grupo, facilitar sua comunicação e desenvolver suas potencialidades, de modo a usá-las da forma mais adequada ao atendimento de suas necessidades. A reflexão sobre a experiência de campo mostra que os grupos terapêuticos se configuraram numa modalidade de assistência clínica de grande valia no trabalho com a população atendida.
\end{abstract}

Palavras-chave: Grupos, Gestalt-terapia, Comunidade.

\begin{abstract}
This article originates from the project Insertion of the Psychologist in the Program of Family Health, developed between 1998 and 2004, with patients with diabetes and hypertension, in a partnership between the Psychology Department of Federal University of Minas Gerais and Municipal Secretariat of Health in Vespasiano (MG). The project was about clinical assistance to the less favored population, culturally and economically, which frequents the PFH. It has the purpose of introducing a proposal of therapeutical groups in the clinical work with people from needy communities, using the premises of Gestalt-therapy. In order to do that, the presentation will explain how the philosophical grounding of Gestalt-therapy and theoretical premises support the methodology and the work of the clinical psychologist, as for working the expansion of consciousness of the group members, facilitating their communication and developing their potentials, in order to use them to help them to appropriately meet their needs. The reflections on the field
\end{abstract}


experience show that therapeutical groups became a worthy clinical assistance modality on the work of the population carried for.

Keywords: Groups, Gestalt-therapy, Community.

\section{I ntrodução}

O presente artigo tem como objetivo explicitar a metodologia dos grupos terapêuticos, fundamentada nos pressupostos da abordagem gestáltica, conforme foi desenvolvida ao longo de um trabalho de assistência psicológica prestado a pessoas moradoras de uma comunidade menos favorecida social e economicamente. Ele é fruto da minha experiência de campo, como coordenadora do projeto de extensão universitária Inserção do Psicólogo No Programa Saúde da Família, realizado entre 1998 e 2004, numa parceria entre a Secretaria Municipal de Saúde de Vespasiano (MG) e o Departamento de Psicologia da Faculdade de Filosofia e Ciências Humanas da Universidade Federal de Minas Gerais. O referido projeto contou também com a participação de alunos do curso de graduação em Psicologia da UFMG.

\section{Contextualizando: O Projeto de Extensão Universitária}

O Programa Saúde da Família foi criado pelo Ministério da Saúde, em 1994, constituindo-se numa proposta de mudança do paradigma centrado na atenção secundária à saúde (voltado para o tratamento de doenças e, consequentemente, enfatizando a figura do médico), para outro que prioriza a atenção primária à saúde, ressaltando a prevenção e valorizando todos os profissionais que compõem a equipe de saúde. Assim, de acordo com a Constituição Federal de 1988, que definiu como princípios do Sistema Único da Saúde a universalização, a integralidade, a descentralização, a hierarquização e a participação popular, o PSF foi implantado priorizando as ações de prevenção, promoção e recuperação da saúde de forma integral e contínua. A equipe de saúde é composta, no mínimo, por um(a) médico(a), um(a) enfermeiro(a), um(a) dentista, um(a) auxiliar de enfermagem e de quatro a seis agentes comunitários de saúde. Os atendimentos são realizados nas Unidades Básicas de Saúde (Centros de Saúde) ou nos domicílios, exercendo-se o "princípio de vigilância à saúde" e o estabelecimento de vínculos de corresponsabilidade na identificação e no atendimento aos problemas de saúde da comunidade. É possível a inserção de outros profissionais da área de saúde na equipe, em função da necessidade da comunidade assistida e da disponibilidade da equipe para tal inclusão (Ministério da Saúde, 2007). 
Foi a partir disso que teve início o referido projeto de extensão universitária em Vespasiano (MG). Ele teve como objetivos:

1. Prestar assistência psicológica a pacientes diabéticos e hipertensos frequentadores do PSF em Vespasiano, a fim de que eles pudessem desenvolver suas potencialidades, de modo a usá-las da forma mais adequada ao atendimento de suas necessidades. Esperava-se, com isso, beneficiar não apenas o seu quadro clínico, mas também despertá-los para seu potencial na construção de uma vida com mais qualidade;

2. Atuar junto à equipe do PSF, colaborando com outros profissionais da Saúde, visando a integrar esforços, estimular a reflexão e a troca de informações sobre a população atendida, de modo a facilitar sua avaliação e evolução clínica;

3. Proporcionar aos estudantes de psicologia a possibilidade de aplicação dos conhecimentos clínicos obtidos no curso no contexto comunitário, numa atuação tanto terapêutica quanto preventiva, mediante o atendimento supervisionado dos pacientes e do trabalho desenvolvido junto à equipe interdisciplinar.

A abordagem gestáltica foi o referencial teórico que fundamentou o trabalho. A metodologia utilizada foi composta por atendimentos individuais, visitas domiciliares, psicoterapia de grupo, grupos terapêuticos, grupos informativos, reuniões de equipe, interconsultas, apresentação do teatro informativo Histórias por um fio: Falando sobre terapia de grupo e supervisão. As atividades desenvolvidas foram realizadas por estagiários do curso de graduação em Psicologia da FAFICH/UFMG selecionados por mim enquanto coordenadora do projeto de extensão (no total, 49 estagiários participaram do projeto de extensão). Assim, em cada uma das nove equipes do PSF em Vespasiano, além dos profissionais da área de saúde que compunham a equipe mínima exigida pelo Ministério da Saúde, havia um estagiário de Psicologia atuando sob minha supervisão (CARDOSO, 2001， 2002; CARDOSO; SANTOS, 2000; CARDOSO; MAYRINK; SANTOS, 2004).

É importante salientar que o enfoque do projeto de extensão se deu a partir da Psicologia Clínica, de forma semelhante àquela descrita por Amatuzzi, Echeverria, Brisola; Giovelli (1996) como “[...] um debruçar-se sobre aquelas pessoas no seu próprio ambiente comunitário, um 'inclinar-se' atencioso, para com elas refletir sobre as questões psicológicas tais como emergiam de sua experiência vivencial" (p. 46-47).

\section{A Abordagem Gestáltica}

Por fugir ao escopo deste artigo o aprofundamento da teoria gestáltica, serão apresentados apenas os pressupostos que 
forneceram o referencial teórico do projeto de extensão universitária Inserção do Psicólogo no Programa Saúde da Família, enfatizando-se aqueles utilizados no trabalho com os grupos terapêuticos.

A fundamentação filosófica da abordagem gestáltica baseia-se em princípios do humanismo, do existencialismo e da fenomenologia. O homem é concebido como um ser de possibilidades e de potencialidades, as quais devem ser valorizadas ao longo do processo terapêutico. Também é considerado como um ser livre para fazer as escolhas de seu projeto de vida, pelas quais deve se responsabilizar. Além disso, é um ser dotado de consciência ativa que atribui a tudo um sentido (conceito fenomenológico de "intencionalidade da consciência"). Assim, toda consciência implica um objeto e todo objeto implica uma consciência a qual the atribui um sentido particular. Na prática, isso significa que cada pessoa percebe o mundo a partir de sua própria perspectiva. No grupo, não há uma perspectiva melhor ou mais correta que a outra (nem mesmo a do coordenador). Portanto, cada pessoa deve buscar sua própria referência sobre o tema em questão e se situar diante do mundo a partir dessa experiência (RIBEIRO,1999).

Quanto ao referencial teórico, a Gestalt-terapia recebeu diversas influências, dentre as quais destaco a psicologia da gestalt, a teoria organísmica de Kurt Goldstein e a teoria de campo de Kurt Lewin, que contribuíram para os conceitos de figura-fundo, totalidade, autorregulação organísmica (homeostase), presentificação da experiência, contato, awareness e fronteira de contato, dentre outros. Outra referência importante foi a filosofia dialógica, proposta pelo filósofo existencialista Martin Buber, que sustenta a compreensão gestáltica da relação terapêutica.

A Gestalt-terapia concebe o homem como um ser em relação consigo mesmo e com o mundo, num constante vir-a-ser e sempre existindo num campo circundante. A partir dessa condição humana, o contato é considerado a matéria-prima da relação humana. Perls, Heferline; Goodman (1997), no primeiro livro publicado sobre Gestalt-terapia (original em 1951), sustentam que todo organismo vive em função da manutenção do diferente, sendo pela assimilação desse diferente que o organismo cresce e se desenvolve. O contato é justamente essa troca com o meio (na chamada fronteira-de-contato) que permite a mudança. $O$ diferente não é introjetado passivamente pelo organismo, mas é assimilado, respeitando as características daquele, num processo de ajustamento criativo. Os autores ressaltam que esse processo ocorre desde as formas vivas mais simples até as mais complexas, incluindo o homem. Abarca desde as funções mais objetivas, como a respiração, até as mais subjetivas (constituição do eu e aquisição da cultura, por exemplo).

Coerente com esse conceito de contato, Ribeiro (1995) afirma que "o modo como uma pessoa faz contato consigo e com o mundo expressa 
igualmente o grau de individuação, maturidade e entrega com que alguém vive em um dado momento". (p. 7)

Quanto mais a pessoa se conecta com sua experiência presente, maior sua possibilidade de estabelecer um contato pleno. Esse conceito é fundamental no trabalho com grupos, pelo fato destes se constituírem num campo onde a pessoa se defronta com a diversidade nos mais variados aspectos, estabelece relações, experimenta o inesperado e revê sua própria referência.

Perls et al (1997) propõem que, na medida que a pessoa aumenta seu contato consigo mesma e com o mundo, ela amplia também sua capacidade de awareness, definida como uma força integradora da estrutura da experiência imediata, seja no nível sensorial, muscular, vegetativo ou afetivo. As alienações, os bloqueios e as resistências geram desconexões entre a pessoa e o mundo, diminuindo sua capacidade de reconhecimento de si nas relações. Awareness implica em contato, mas nem todo contato implica em awareness.

Yontef (1993) define awareness como "uma forma de experienciar. É o processo de estar em contato vigilante com o evento de maior importância no campo indivíduo/meio, com total suporte sensóriomotor, emocional, cognitivo e energético". (p. 245)

Não existe na língua portuguesa uma palavra que exprima o significado de awareness, por isso os teóricos mantiveram a palavra original. A palavra mais próxima é conscientização, mas ela não explicita o sentido de contato, excitação, fluxo e livre formação de gestalten, implícito neste conceito. Assim, o objetivo maior da abordagem gestáltica é ajudar a pessoa a restabelecer sua capacidade de se tornar aware.

\section{A Concepção de Grupos na Abordagem Gestáltica}

A concepção gestáltica de grupo que adotei ao longo do trabalho em Vespasiano se baseia, principalmente, nas contribuições da teoria de campo e na fenomenologia, buscando facilitar nas pessoas a capacidade de se tornarem mais aware de si mesmas. Perls et al. (1997) enfatizam a relação constante entre organismo e meio ao sustentarem que a experiência é função da fronteira entre ambos. Eles afirmam:

Em toda ou qualquer investigação biológica, psicológica ou sociológica temos que partir da interação entre o organismo e seu ambiente. Não tem sentido falar, por exemplo, de um animal que respira sem considerar o ar e o oxigênio como parte da definição deste, ou falar de comer sem considerar a comida, ou de enxergar sem luz, ou de locomoção sem gravidade e um chão para apoio, ou da fala sem comunicadores. (PERLS et al., 1997, p. 42) 
A noção de campo engloba tanto o organismo quanto o ambiente. Yontef (1993) define campo como "uma totalidade de forças mutuamente influenciáveis que, em conjunto, formam um todo interativo unificado" (p. 297). Nesse sentido, a abordagem de campo é holística, pois todos os eventos que nele ocorrem resultam da interação das forças presentes, configurando-se, portanto, numa teia sistemática de relacionamentos. Isso implica que os fenômenos são integrados e determinados pelo campo todo. Assim, trabalhar nessa perspectiva é descrever a totalidade, da qual os eventos e as pessoas são apenas uma parte. Mais do que segmentar, classificar ou interpretar, trata-se de observar, descrever e compreender a rede de relações entre as partes que o compõem.

Robine (2001) considera que o conceito de campo tem aproximação com a fenomenologia, em razão de ele se referir ao espaço vital das percepções, ações, sentimentos e significados de cada pessoa. Portanto, o que uma pessoa experimenta como campo, dificilmente será experimentado por outra, em função de suas próprias vivências. Essa perspectiva me permite dizer que, apesar das aparências, vivemos em mundos completamente diferentes.

Nesse prisma, sujeito e objeto deixam de estar em oposição, pois a experiência inclui o sentido produzido pela pessoa no seu ambiente. Assim, torna-se impossível falar de um campo (situação ou evento) como possuidor de uma realidade independente e objetiva, separada da experiência que a pessoa tem dele. Para conhecer a experiência que se tem do campo é preciso conhecer a perspectiva da pessoa.

Esses pressupostos são de grande valia para a compreensão dos fenômenos grupais na abordagem gestáltica, pois ressaltam a relação, a atividade e as forças dinâmicas experimentadas no grupo. As influências entre cada participante e aquelas do grupo como um todo são mútuas, múltiplas e complexas. Os eventos experienciados são co-construídos pela interação entre os estímulos e a reflexão que se tem deles. Isso impossibilita que se tenha uma única perspectiva válida do grupo, mas tantas quantas forem seus integrantes. $O$ máximo que se pode fazer é atualizar as experiências destes para conhecê-las, saber seus sentidos e quais se aproximam, pois o grupo é um campo construído momento a momento, constantemente (FAIRFIELD, 2004).

Essa concepção de grupo prioriza a dimensão processual, que compreende $\mathrm{o}$ grupo como um fenômeno em constante transformação, a partir das relações estabelecidas entre seus membros e entre o próprio grupo e o contexto no qual ele ocorre. Sua realidade externa (o que acontece a cada momento tanto no nível verbal quanto no não-verbal, bem como as contingências do lugar onde ele ocorre) afeta a realidade interna de cada um dos seus membros (incluindo a do coordenador). Da mesma forma, as 
vivências e os processos internos de cada participante transformam a realidade do grupo como um todo. Assim, trata-se de uma totalidade cujas partes são interdependentes, sejam elas conscientes ou inconscientes, coerentes ou divergentes, claras ou ambíguas.

Ribeiro ilustra isso ao afirmar que:

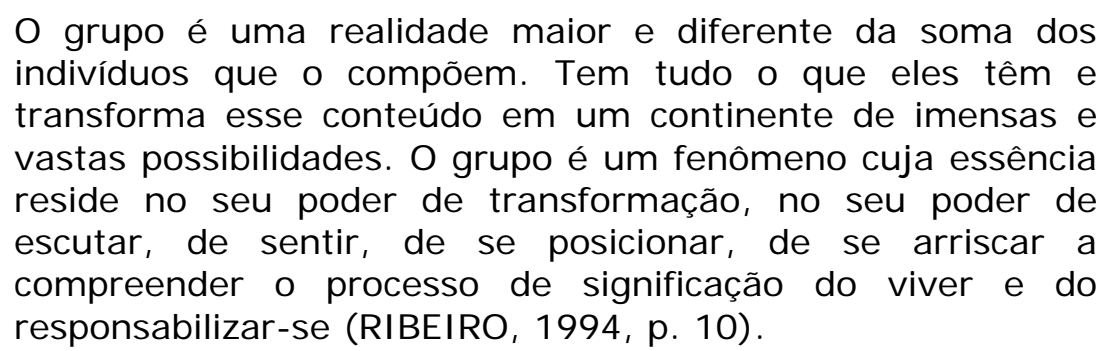

A proposta de Yalom (1995) sobre trabalhos com grupos também serviu como referencial teórico nas atividades desenvolvidas no projeto de extensão em Vespasiano, especialmente no que concerne aos fatores terapêuticos do grupo propostos pelo autor: instilação de esperança, universalidade, oferta de informações, altruísmo, desenvolvimento de técnicas de socialização, reedição corretiva do grupo familiar primário, comportamento imitativo, catarse, fatores existenciais, coesão grupal e aprendizagem interpessoal. Eles propiciaram a compreensão do material emergente ao longo do processo grupal, bem como em situações específicas da interação dos participantes.

Essa concepção descrita anteriormente teve forte influência na minha maneira de propor e de conduzir os grupos no trabalho de campo. Desde os seus objetivos, até a forma como os temas foram escolhidos, busquei valorizar a perspectiva de seus participantes, resgatar e legitimar sua experiência conforme explicitada por eles durante o encontro. E foi justamente essa postura fenomenológica de abertura, facilitação e de confirmação das pessoas que me possibilitou desenvolver a proposta de grupos terapêuticos, conforme descreverei a seguir.

\section{Os Grupos Terapêuticos}

Na experiência do projeto de extensão, o grupo foi se fortalecendo (em comparação às outras modalidades de atendimento), devido à procura da comunidade por esse tipo de assistência. Inicialmente, propus grupos de espera no dia em que os pacientes compareciam ao Centro de Saúde para controle da glicemia e/ou pressão arterial. Porém, tais grupos de espera tiveram um aumento progressivo de participantes, sendo que alguns destes, inclusive, passaram a frequentar os grupos mesmo nos dias em que não estava agendada 
sua consulta médica. Com essa adesão dos pacientes, a dinâmica dos encontros foi se modificando e passei a chamá-los de grupos terapêuticos, os quais tinham objetivos distintos daqueles dos grupos de espera, conforme explicito a seguir.

Os grupos terapêuticos se davam da seguinte forma: os pacientes compareciam regularmente ao Centro de Saúde Pública para realizarem o controle da glicemia e/ou da pressão arterial junto à equipe de saúde. Eram pessoas simples, usuárias do Serviço Público de Saúde, moradoras da região mais pobre de Vespasiano e, em sua maioria, com mais de 40 anos, diabéticas e/ou hipertensas, frequentadoras do PSF daquele município. Enquanto aguardavam a consulta, eram convidadas a participar do grupo da Psicologia (eventualmente, elas participavam de grupos com outros profissionais da área de saúde). Eles eram temáticos, com cerca de 60 minutos de duração, sem continuidade entre eles, com composição flutuante, mistos quanto à patologia e ao sexo, com tema previamente definido e esgotado a cada encontro. Tinham como objetivo oferecer um espaço onde as pessoas pudessem expressar livremente sua experiência em relação ao tema proposto, buscandose, com isso, facilitar a comunicação, ampliar a conscientização das pessoas assistidas sobre suas experiências e resgatar a responsabilidade delas não apenas em relação à doença e ao tratamento, mas também em relação à sua vida de modo geral. Em outras palavras, buscava-se trabalhar a vivência de seus membros a partir do material emergente, enfocando o aspecto emocional, as crenças e ações de cada pessoa, tendo também conotação pedagógica, na medida em que, ocasionalmente, eram difundidas informações.

A partir da postura fenomenológica de abertura para aprofundar nos grupos as questões que mais mobilizavam as pessoas, foi trabalhada uma ampla gama de temas, todos apontados nos encontros como experiências significativas e mobilizadoras por parte dos pacientes. Assim, em função do que emergia no processo grupal, foram abordados os seguintes temas: apresentação pessoal, receita de saúde e doença, a vivência de tomar remédios, família, a vivência de ser diabético ou hipertenso, sentimentos, a experiência religiosa, preocupação, autocuidado, ser responsável, a vivência dos limites, violência, a vivência de frequentar o PSF, dificuldades da vida, avaliação dos grupos propostos pela Psicologia e despedida (por ocasião da saída dos estagiários do projeto de extensão). Eles serviam apenas como um estímulo para a expressão dos participantes em relação àquilo que vivenciavam no momento. Quando emergia uma questão que mobilizava mais o grupo, era essa a ser aprofundada, mesmo sendo distinta do tema proposto inicialmente. Além do diálogo, eram utilizados recursos expressivos (lápis coloridos, papel, revistas, colagens, textos, etc.) visando a 
facilitar o contato e a expressão das pessoas sobre sua experiência. Aos poucos, mesmo as pessoas que não estavam agendadas para consulta médica iam ao Centro de Saúde para participar dos grupos terapêuticos.

Como coordenadora do projeto de extensão, solicitei a todos os estagiários que escrevessem um relatório ao final das atividades, com a descrição detalhada das mesmas, o qual me era entregue nas supervisões. No caso dos grupos, além desse relatório, recebi inúmeras colagens e desenhos confeccionados pelos seus participantes, que eles preferiram deixar com o estagiário. Isso propiciou um grande acervo das produções criadas por eles ao longo do projeto de extensão universitária.

O único tema definido previamente por mim, enquanto coordenadora do projeto de extensão, era a "apresentação". Sempre que um estagiário iniciava sua participação numa equipe, no primeiro encontro com o grupo ele propunha uma dinâmica que tinha como objetivo facilitar a apresentação dele e a dos participantes. $\mathrm{Na}$ supervisão, nós conversávamos sobre os temas que emergiram nesse primeiro encontro e, a partir desse material, definíamos qual seria o tema do segundo encontro, e assim, sucessivamente. Todos os temas sugeridos aos grupos foram escolhidos dessa forma. Então, por exemplo, numa "dinâmica da apresentação", os participantes falaram muito sobre a importância de cuidar dos sentimentos, além do corpo e da alma, para melhorarem sua saúde. Assim, o próximo grupo teve como objetivo facilitar a expressão dos sentimentos experimentados por eles.

Nessa ocasião, em especial, falou-se muito sobre "preocupação". Alguns chegaram a verbalizar que não dava para controlar a pressão arterial ou a glicemia com tanta preocupação. Propusemos, então, outro grupo acerca desse tema, solicitando, após um aquecimento inicial, que seus participantes expressassem da melhor forma (falando, desenhando ou selecionando uma figura de revista, por exemplo) sua experiência de "preocupação". Perguntas como "O que é essa 'preocupação'?", "Como ela acontece na sua vida?", "O que você pode nos falar ou nos mostrar dela nesse momento?" eram feitas a fim de facilitar o contato dos participantes com sua vivência do tema, bem como seu depoimento para os demais membros do grupo. Com isso, por exemplo, um participante, ao desenhar um círculo, com contorno e preenchimento pretos escreveu: A preocupação rola como uma bola. Mas não rola. Perturba. Em outro grupo, um membro desenhou um círculo e o coloriu de vermelho, dizendo que era assim a sua preocupação: Vermelha por causa da intensidade; é muito forte. Redonda porque parece um rodamoinho. A gente não sai do lugar. Outra pessoa, ao escolher uma figura com a foto de uma mulher com o cenho franzido e um pica-pau a bicar sua cabeça, disse (conforme consta na colagem com a gravura): Às 
vezes, sinto que a minha cabeça está confusa, cheia de preocupações.

Houve um período em que alguns médicos da equipe de saúde do PSF solicitaram a nossa ajuda, para compreender o motivo pelo qual vários pacientes não estavam fazendo uso correto dos medicamentos prescritos. Por isso, sugerimos como tema a ser trabalhado nos grupos terapêuticos a vivência de fazer uso de medicamentos. À pergunta "Como é para você ter que tomar remédios todos os dias?", uma pessoa mostrou um recorte com a figura de uma prisão, e começou a descrever sua vivência de ser "prisioneira" do remédio. Nesse mesmo grupo, outro membro selecionou a foto de um posto de gasolina, dizendo que, do mesmo modo que um carro não funciona sem gasolina, ele precisava dos medicamentos para seguir sua vida. Um rico diálogo entre o grupo sucedeu-se a partir de então.

Entretanto, em diversas ocasiões, emergiu a seguinte situação: por se tratarem de pessoas muito simples, um grande número delas não sabia ler, nem escrever e, por isso, não sabiam ver as horas. Consequentemente, tinham dificuldades em tomar os remédios "de 12 em 12 horas", ou "de 6 em 6 horas", mas sentiam-se envergonhadas de dizerem isso para o médico ou para a enfermeira e acabavam fazendo confusão não apenas nos horários, mas também no remédio a ser tomado. Ao percebermos isso, expusemos para a equipe de saúde a situação, que experimentou fazer desenhos indicativos do horário de ingestão do medicamento, como por exemplo, o sol, mostrando que ele deveria ser tomado pela manhã, e a lua e estrelas, indicando ser a noite o período de consumo do remédio. Voltamos aos grupos para checar o entendimento das pessoas e foi curioso, quando algumas delas entenderam literalmente a indicação do sol e perguntaram se era para suspender o medicamento em dias de chuva. A partir disso, os médicos se mostraram mais cuidadosos com a maneira pela qual as informações eram transmitidas aos pacientes. Isso também acarretou novas reflexões entre os profissionais sobre a qualidade da comunicação entre a equipe de saúde e a comunidade assistida.

Em outro momento, num encontro cujo tema sugerido foi a vivência de ser hipertenso, uma pessoa escolheu a imagem de um dragão, dizendo: Eu escolhi essa daqui porque, no meu pensamento, a pressão alta é uma fera que a gente tem dentro da gente, dentro de casa. Aqui tem um dragão. A pressão alta está ligada na gente o tempo todo. E se a gente não cuidar, essa fera abraça a gente. Em um outro grupo, uma mulher escolheu uma carro em chamas e disse, segundo o relatório da estagiária: Eu escolhi essa figura porque me lembra que qualquer coisinha faz minha pressão subir. Eu estou calma, tranquila, aí acontece um aborrecimento e pode ver que a pressão já subiu...". 
Já em outro grupo sobre a vivência de ser diabético, uma participante expressou sua revolta, afirmando ser a diabetes uma "doença do diabo", tanto que tem "diabetes" tem quase todas as letras da palavra "diabo". Essa fala mobilizou todo o grupo, provocando o compartilhar de diferentes perspectivas sobre a vivência de ser diabético. Outra pessoa selecionou a figura de uma estrada, dizendo que a diabetes é como uma estrada pela qual a pessoa vai caminhando, porém só de ida, pois é uma doença que não tem cura.

Um tema que mobilizou bastante os membros dos grupos terapêuticos foi "A receita de saúde e doença". Nos encontros com essa proposta, perguntava-se a eles o seguinte: "Se a saúde tivesse uma receita, quais seriam os ingredientes?" Respostas como "tomar os remédios", "fazer caminhadas", "fazer a dieta", "ter paz na família", "se cuidar" foram algumas sugeridas. Na medida em que eram faladas, o estagiário escrevia num painel aquilo que era dito pelas pessoas. Depois que, na perspectiva do grupo, a "receita de saúde" estava completa, era solicitada a "receita de doença", que gerava respostas como "falta de dinheiro", "problemas na família", "passar raiva", "beber", "fumar", "comer o que não deve", "brigas", etc. Quando encerravam-se os ingredientes, os quais também eram anotados, o estagiário lia as duas receitas para o grupo e fazia a seguinte pergunta para seus membros: "Qual a receita que você está seguindo mais?" Em geral, as pessoas passavam a expressar suas vivências em relação aos hábitos saudáveis e aos promotores de doença, falavam das suas dificuldades em mudar seus hábitos e trocavam experiências sobre seus recursos para contornar as dificuldades do cotidiano e para melhorar a qualidade de vida. Ao final do encontro, era proposto que cada um escolhesse um ingrediente da receita de saúde para incluir no seu dia-a-dia e outro da receita de doença para tentar evitar. Em ocasiões posteriores, diversas pessoas contaram para os estagiários as reflexões geradas a partir desse tema e as mudanças de hábitos decorrentes disso.

Vale ressaltar também que, ao consultar o material compilado ao longo da experiência de campo, percebi que a família era um tema sempre presente nos grupos, direta ou indiretamente, mesmo que não se tratasse do principal assunto proposto no encontro. Com isso, propus grupos com o objetivo de investigar a vivência deles de família (CARDOSO; FÉRES-CARNEIRO, 2008), e foi a partir dessa experiência de campo que evidenciei importância de realizar uma pesquisa sobre esse tema em uma comunidade popular (CARDOSO, 2007).

Pelo fato de os grupos terapêuticos se configurarem numa metodologia nova, desenvolvida a partir de minhas reflexões sobre o desenvolvimento do projeto de extensão universitária, propus como um dos temas a avaliação dos grupos da psicologia, ao perguntar "Como é para você participar dos grupos da Psicologia?" Através de 
depoimentos, de colagens e de desenhos, o retorno foi bastante positivo. Um senhor disse o seguinte: As palavras são como pedras. Elas pesam quando ficam guardadas dentro da gente. Mas aqui no grupo, a gente não só fica mais leve porque coloca as pedras para fora, como também constrói com as pedras que cada um traz. Em outro momento, uma senhora fez uma colagem com três figuras: um golfinho, uma árvore com frutas e um grupo de pessoas com idades variadas. Segundo o relatório do estagiário, ela afirmou: Aqui, a gente fica alegre como esses golfinhos. É como se a gente viesse refrescar a cabeça. A gente aprende a cuidar da gente, como tem que cuidar dessa plantinha. Aqui nós somos uma família, com todo mundo animado e humilde. Uma terceira pessoa selecionou a figura de um homem com uma expressão de desânimo e outra de uma corredora alcançando a linha de chegada e disse que quando descobriu a diabetes ficou desanimada como o homem, mas que, depois de começar a participar do grupo, sentia muita vontade de vencer. Uma pessoa, por sua vez, escolheu um recorte de revista com diversos animais, dizendo que, do mesmo modo que aquela figura mostrava a variedade, no grupo, as pessoas eram diferentes e mesmo que cada uma visse a vida da sua maneira, ali elas estavam juntas, se ajudando, e isso era muito bom.

Enfim, essas foram algumas descrições parciais dos grupos, as quais tiveram por objetivos esclarecer como a proposta dos grupos terapêuticos se deu na prática e ilustrar alguns retornos dados pelos participantes, explicitando como aqueles se constituíram numa oportunidade de intensa troca de experiências entre as pessoas que deles participaram e no exercício do diálogo a partir do material expresso por elas, em função do tema abordado.

\section{Considerações Finais}

A experiência de campo mostrou que as pessoas moradoras das comunidades populares, frequentemente, são desacreditadas e desconfirmadas no seu saber e no seu conhecimento de vida, o que elas, muitas vezes, ampliam para si mesmas como um todo e para os diversos aspectos de sua vida. A postura fenomenológica, proposta pela abordagem gestáltica, de acolhimento, de disponibilidade para escutar genuinamente as pessoas atendidas e o interesse por suas vivências, bem como a valorização da experiência de vida dos participantes do grupo, permitiram uma aproximação maior entre estes e os estagiários de psicologia. Diversas vezes, as pessoas disseram se sentir mais à vontade para falar de sua história e de questões ligadas à doença no grupo, do que na consulta médica. Acreditamos que isso ocorreu devido à legitimação da experiência de cada pessoa e ao respeito pela diferença, conforme propõem a teoria 
de campo e a fenomenologia (FAIRFIELD, 2004; PERLS et al., 1997; RIBEIRO, 1994). Isso facilitou o acesso do estagiário às experiências das pessoas assistidas e à sua compreensão de mundo. Além disso, o grupo foi reconhecido por diversos participantes como uma oportunidade para pensar sobre a vida e sobre os problemas cotidianos, aprender com a diversidade de perspectivas dos outros integrantes do grupo e aprofundar seu auto-conhecimento.

A reflexão sobre a experiência com os grupos terapêuticos demonstrou também que eles se configuraram numa oportunidade de expressão das vivências e de troca de experiências, tornando-se uma valiosa fonte de aprendizagem, promotora de crescimento, conforme sugerem os fatores terapêuticos descritos por Yalom (1995).

A partir dos relatos de várias pessoas e dos profissionais da equipe de saúde do PSF, verificou-se que a participação nos grupos terapêuticos proporcionou nos seus membros um aumento da responsabilidade pessoal em situações cotidianas (através de novos posicionamentos nas relações familiares, maior capacidade de fazer escolhas, busca por melhorar a qualidade de vida, etc.), maior engajamento no autocuidado, reformulação da postura em diversos aspectos da vida, maior capacidade de estabelecer contato consigo e com os outros, ampliação dos recursos de que passaram a dispor para lidarem melhor com suas dificuldades e maior adesão das pessoas ao tratamento de saúde.

Pelo exposto, ressaltamos a importância da utilização do grupo como forma de atender à demanda do público-alvo do projeto de extensão universitária Inserção do Psicólogo no Programa Saúde da Família, abrindo uma possibilidade diferente daquela dos grupos de psicoterapia, com seus objetivos e enquadre particulares. Para isso, entendo ter sido fundamental a atenção às questões que sustentam a proposta de assistência psicológica em grupo: por que propor esse grupo (qual a sua justificativa)? Para que realizá-lo (qual seu objetivo)? Para quem (quais as características e demandas daquelas pessoas a quem o grupo se destina)? Como desenvolvê-lo (a partir das competências e habilidades do coordenador e do local onde ele acontecerá)?

O foco nessas questões, aliado aos pressupostos da abordagem gestáltica e às relações estabelecidas nos encontros entre os participantes e entre estes e os coordenadores dos grupos permitiram o desenvolvimento e a compreensão do processo grupal, o que parece ter proporcionado a melhoria na qualidade do contato das pessoas consigo mesmas e com sua vida, de modo geral. 


\section{Referências Bibliográficas}

AMATUZZI, M.M.; ECHEVERRIA, D.F.; BRISOLA, E.B.V. ; GIOVELLI, L.N. Psicologia na comunidade: Uma experiência. Campinas: Alínea, 1996.

CARDOSO, C.L. O gestalt-terapeuta na comunidade: Des-cobrindo a autenticidade do sujeito. Revista do VII Encontro Goiano da Abordagem Gestáltica, Goiânia, n. 7, ano 2001, p. 95-108 Inserção do psicólogo no Programa Saúde da Família. Psícologia: Ciência e Profissão, Brasília, v. 22, n.1, p. 2-9, 2002.

Um Estudo Fenomenológico sobre a Vivência de Família: Com a palavra, a comunidade. 2007, 212 f., Tese (Doutorado em Psicologia Clínica). Pontifícia Universidade Católica do Rio de Janeiro, Rio de Janeiro.

CARDOSO, C.L.; FÉRES-FÉRES-CARNEIRO, T.F. Sobre a família: Com a palavra, a comunidade. Revista Estudos e Pesquisas em Psicologia, Rio de Janeiro, V. 8, n. 2, p. 523-539, $1^{\circ}$ semestre de 2008.

CARDOSO, C.L.; MAYRINK, A.; SANTOS, G.F. Aplicações da Gestaltterapia no trabalho clínico com comunidades. Revista de Gestalt, São Paulo, n. 13, 2004, p.7-15.

CARDOSO, C.L.; SANTOS, P.L.C. Histórias por um fio: Falando sobre psicoterapia de grupo. I nsight: Psicoterapia e Psicanálise, São Paulo, n. 108, p. 25-29, jul/2000.

FAIRFIELD, M. A. Gestalt groups revisited: A phenomenological approach. Gestalt Review, South Wellfleet, v. 8 n.3, p.336-357, 2004

PERLS, F., HEFfERLINE, R. ; GOODMAN, P. Gestalt-terapia. São Paulo: Summus, 1997.

RIBEIRO, J.P. Gestalt-terapia: Refazendo o Caminho. São Paulo: Summus, 1985.

. Gestalt-terapia: O processo Grupal - Uma Abordagem Fenomenológica da Teoria de Campo e Holística. São Paulo: Summus, 1994.

$\overline{1} \overline{9} \overline{9} \overline{.}$

O Ciclo do Contato: Gestalt - Temas Básicos. Brasília: Ser, $\overline{1} \overline{9} \overline{9} \overline{.}$

Gestalt-terapia de Curta Duração. São Paulo: Summus, ROBINE, J. M. From field to situation. In:

(Ed.) Contact and

Relationship in a Field Perspective. Bordeaux: L'exprimerie, 2001, 95-107.

YALOM, I.D. The Theory and Practice of Group Psychotherapy. New York: Basic Books, 1995.

YONTEF, G. Awareness, Dialogue, Process: Essays on Gestalt Therapy. New York: The Gestalt J ournal Press, 1993. 


\section{Endereço para correspondência}

Claudia Lins Cardoso

Universidade Federal de Minas Gerais, Faculdade de Filosofia e Ciências Humanas, Departamento de Psicologia, Av. Antônio Carlos, 6.62, sala 4080,Campus Pampulha, CEP 31270-901, Belo Horizonte-MG, Brasil

Endereço eletrônico: clins.bh@terra.com.br

Recebido em: 30/03/2008

Aceito para publicação em: 21/01/2009

Editor Responsável: Eleonôra Torres Prestrelo

\section{Notas}

*Doutora em Psicologia Clínica - PUC - Rio de Janeiro 